ARTIGO DE REVISÃO

ISSN 1677-5090

(C) 2017 Revista de Ciências Médicas e Biológicas

DOI: http://dx.doi.org/10.9771/cmbio.v16i2.15078

\title{
Aplicabilidade do cromossomo X no DNA forense
}

\author{
Chromosome $X$ of applicability in DNA forensic
}

\author{
Andressa Paula Leite Barros Machado', Raisa Fernandes de Souza Leite ${ }^{1}$, Rejane da Silva Sena Barcelos ${ }^{2 *}$ \\ ${ }^{7}$ Acadêmica de Biomedicina e Farmácia, PUC - Goiás; ²Doutora em Biologia Animal pela Um, Professora Adjunto \\ PUC-Goiás. Superintendente de Polícia Técnico-Científica do Estado de Goiás.
}

\begin{abstract}
Resumo
Introdução: os casos de identificação humana com a ausência do pai se tornam de difícil solução com marcadores moleculares autossômicos, do cromossomo Y e situados no DNA mitocondrial. Objetivo: contribuir com a solução destes casos utilizando o polimorfismo genético de marcadores moleculares situados no cromossomo X. Metodologia: buscas foram realizadas em bases de dados nacionais e internacionais até novembro de 2015. Foram selecionados artigos relacionados com o uso de marcadores moleculares e com a solução de casos de paternidade com e sem a ausência do suposto pai. Discussão: os achados na literatura mostram que casos de paternidade com a ausência do pai podem ser solucionados com o polimorfismo do cromossomo X (repetições de tetranucleotídeos), inclusive com menos marcadores em relação às demais classes de marcadores, pois o padrão de herança mostrase diferente entre os pais. Conclusão: a principal aplicabilidade do polimorfismo do cromossomo X situa-se nos casos complexos de identificação humana que não poderiam ser solucionados devido à ausência do material biológico de parentes.
\end{abstract}

Palavras-chave: Cromossomo X. Genética Forense. Identificação Humana. Polimorfismo.

\begin{abstract}
Introduction: cases of human identification, with the father's absence become difficult to solve with autosomal molecular markers of the $Y$ chromosome and located on the mitochondrial DNA. Objective: contribute to the solution of these cases using the genetic polymorphism of molecular markers located on chromosome X. Methodology: searches were carried out in national and international databases until November 2015. We selected articles related to the use of molecular markers and the solution for paternity cases with and without the absence of the alleged father. Discussion: the findings in the literature show that paternity cases with the absence of the father can be solved with the polymorphism of the X chromosome (repeats tetranucleotideos), including fewer markers in relation to other classes of markers because the inheritance pattern shows different between the parents. Conclusion: the main applicability of $X$ chromosome polymorphism lies in the complex cases of human identification that could not be solved due to the absence of biological material from relatives.
\end{abstract}

Keywords: X chromosome. Forensic Genetics. Human Identification. Polymorphism

\section{INTRODUÇÃO}

Allec Jeffreys, em 1985, analisando a molécula de DNA (ácido desoxirribonucléico) vislumbrou a perspectiva de esta molécula ser utilizada como um método de identificação humana, solucionando um caso de imigração na Inglaterra (JEFFREYS; BROOKFIELD; SEMEONOFF, 1985). O caso envolveu uma família africana, que residia no Reino Unido e teve um dos filhos proibido de ingressar no país pelas autoridades locais. As ciências forenses recebeu a atenção do mundo científico quando o pesquisador Allec Jeffreys analisando a molécula de DNA comprovou o vínculo entre mãe e filho contestado (JEFFREYS, 2013).

Aliado a esta nova metodologia, em 1987, o exame de DNA foi aceito pela primeira vez pela Corte de Justiça do Reino Unido como prova criminal, levando a condenação de um indivíduo que estuprou e assassinou duas jovens

Correspondente/Corresponding: *Rejane da Silva Sena Barcelos - End: Avenida Universitária, 1440 - Setor Universitário. CEP 74605-010-Goiânia-GO. - Tel: (62) 99637-4025 - E-mail: rejanesena@yahoo.com.br nos anos de 1983 e 1986. Neste caso, foram coletadas amostras de sangue de todos os homens adultos que residiam na vila Narborough e comparadas com o sêmen coletado das vítimas. Foi comprovado através do exame de DNA que o perfil genético de Colin Pitchfork era idêntico ao do sêmen encontrado nas vítimas (JOBLING, 2013).

Essa metodologia molecular pode ser considerada uma técnica confiável utilizada para diferenciação de indivíduos. Este método também pode ser utilizado na área forense especialmente em análises de locais de crime, onde podem ser coletados materiais biológicos de diferentes fontes; muitas vezes em quantidade escassa, degradada, contaminada, entre outros (ZIETKIEWICZ et al., 2012).

Em um local de crime, vestígios que contenham uma mínima quantidade de material biológico, podem fornecer informações valiosas para solucionar casos através de um exame de DNA. Por isso, esta técnica revolucionou as investigações criminais, com a possibilidade de acusar e, principalmente, inocentar pessoas (FRUMKIN et al., 2010; GODINHO, 2014). 
Em um laboratório de genética forense existem algumas particularidades que dificultam a obtenção de um perfil genético completo, dentre elas, as mais frequentes são amostras biológicas degradadas e ausência de ascendentes e/ou descendentes. Devido a essas dificuldades, nessas análises utilizam-se além dos marcadores moleculares nucleares, os situados no cromossomo $\mathrm{X}$ e $\mathrm{Y}$, além do DNA mitocondrial (SANTOS, 2014).

\section{DNA (Ácido Desoxirribonucléico)}

A molécula de DNA foi descrita em 1953 por dois cientistas, Francis Crick e James Watson que descreveram uma macromolécula composta por duas fitas dispostas em dupla hélice, em forma de espiral, que são formadas por nucleotídeos. Cada nucleotídeo é composto por três unidades básicas: um grupamento fosfato, uma pentose e uma base nitrogenada. As bases nitrogenadas são divididas em purinas: adenina (A) e guanina (G) e pirimidinas: timina (T) e citosina (C) (WATSON; CRICK, 1953).

Todas as informações genéticas estão contidas na molécula de DNA, situado no núcleo celular (DNA nuclear) ou na mitocôndria (DNA mitocondrial) (OLIVEIRA, 2012). O DNA nuclear apresenta-se como diplóide, com vinte e três pares de cromossomos, dos quais vinte e dois (22) são autossômicos e um (1) par sexual, cromossomos $\mathrm{X}$ e Y (VELHO; GEISER; ESPINDULA, 2013). Estruturalmente, o cromossomo um (1) mostra-se como o maior deles e o cromossomo $Y$ considerado o menor dentre eles (GRIFFITHS et al., 2009).

Já o DNA mitocondrial, comporta-se como marcador genético uniparental, de origem matrilinear, herança haplotípica, com grande interesse na área forense contendo mais de 5.000 cópias por célula. Sua estrutura apresenta-se em forma de dupla fita circular proporcionando uma maior resistência à ação de exoenzimas. Possui dezesseis mil quinhentos e sessenta e nove (16.569) pares de bases (pb) descritas em 1981 (ANDERSON et al., 1981). Foram caracterizadas as regiões HVI e HVII que podem ser analisadas pelo método de sequenciamento (SANCHES, 2013).

\section{DNA Forense}

A evolução da ciência e tecnologia proporcionou a análise da molécula de DNA tornando-se de suma importância para resolução de casos forenses, em especial os casos criminais, os quais são solucionados em função à sensibilidade das técnicas que são empregadas no exame. A metodologia pode auxiliar na solução de casos através de análises moleculares de vestígios biológicos deixados por suspeitos em locais de crime ou mesmo em vítimas, como é o caso de homicídios e/ou estupros (HOU, 2009).

Em casos onde a identificação da vítima não é possível (acidentes automobilísticos com carbonização do corpo, desastres aéreos, corpos mutilados, restos mortais não identificados, atos de terrorismo e catástrofes naturais), o exame de DNA também se torna uma ferramenta indispensável (BONACCORSO, 2005).

\section{Marcadores Moleculares}

No genoma humano existem mais de três bilhões de nucleotídeos, sendo que apenas 0,1\% apresentam uma variação na sequência, denominada polimorfismo, o que possibilita a diferenciação entre indivíduos (LI et al., 2009). O polimorfismo pode ser de comprimento ou de sequência, onde, o primeiro é considerado o marcador mais utilizado na identificação humana (OLIVEIRA, 2012).

Os marcadores moleculares utilizados em análises genéticas de maior interesse na área forense são os STRs (Short Tandem Repeats), SNPs (Single Nucleotide Polymorphism) e Indels (inserção/deleção) (MATTE, 2011). Atualmente, na rotina forense, os marcadores moleculares do tipo STR são os mais utilizados, constituindo uma ferramenta fundamental e valiosa na análise de perfis genéticos (TAN et al., 2013). Estes apresentam além de alto grau de polimorfismo, uma menor quantidade de pares de bases, entre 2 a 7, ideais para análise de amostras forenses (CHEN et al., 2009).

Os marcadores do tipo SNP, apesar de serem encontrados em abundância no genoma humano, apresentam menor variação gênica em relação aos marcadores do tipo STR, além de apresentarem baixo poder discriminativo (SILVA et al., 2013). Apresentam variações de um único nucleotídeo em uma determinada sequência da molécula de DNA, podendo verificar em uma base, como por exemplo, C/T ou um A/G (BUDOWLE; DAAL, 2008).

Os marcadores do tipo indels constituem outro tipo de polimorfismo contido no genoma humano. Trata-se de inserções ou deleções em determinada região da sequência da molécula de DNA, que podem variar de um a centenas de nucleotídeos (LI et al., 2013).Assim como os SNPs, os indels são geralmente bialélicos, isto é, apresentam dois alelos para cada loci analisado. Ainda não são rotineiramente utilizados nos laboratórios forenses, porém futuramente poderão ser indispensáveis na identificação humana (MATTE, 2011; SILVA et al., 2013).

Os marcadores STR são amplificados através da técnica de PCR (Polymerase Chain Reaction), que permite amplificar milhares de cópias de moléculas de DNA, mesmo que estas estejam degradadas ou em quantidade exígua (GOÉS, 2010). Além da utilização da metodologia de PCR, o sistema de amplificação simultânea de vários loci (sistema multiplex) facilitou a análise desses marcadores, pois essa metodologia proporciona a leitura de vários alelos juntos, amplificados em menor tempo, bem como, possibilita o uso de uma ínfima quantidade de DNA no procedimento (JOBIM; COSTA; SILVA, 2005).

A nomenclatura dos marcadores do tipo STR (Figura 1) segue uma ordem padronizada, em que a primeira letra que representa o marcador é a letra “ $D$ ”, de molécula de DNA, após vem a identificação do cromossomo onde o marcador está localizado, no caso dos cromossomos sexuais utiliza-se " $X$ " e "Y" e dos autossômicos de um (1) a vinte e dois (22). Em terceiro lugar, vem à letra " $\mathrm{S}$ " (single copy sequence) que significa cópia de sequência única, e por último a localização da sequência no cromossomo onde o marcador foi descrito (BUTLER, 2005). 
Figura 1 - Nomenclatura de um marcador STR autossômico

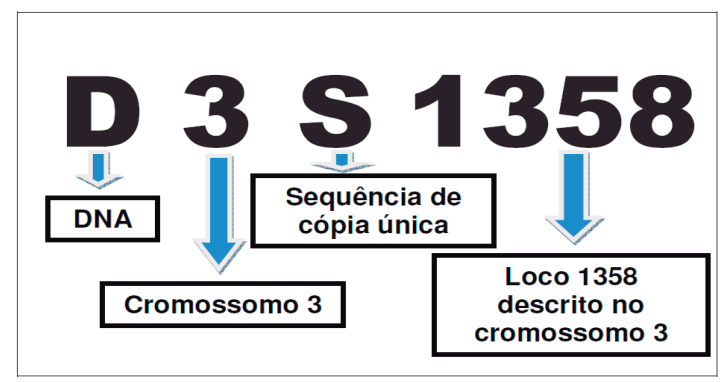

Fonte: Adaptado de Butler (2005)

O FBI (Federal Bureau of Investigation) padroniza uma quantidade ideal de loci STR para resolução de casos em Laboratórios de Genética Forense. Primeiramente foi recomendada uma quantidade de, no mínimo, 13 regiões autossômicas, além do gene da amelogenina para determinação do gênero sexual (BUTLER; HILL, 2012). Porém, o $\mathrm{FBI}$ publicou recentemente novas recomendações que sugeriram uma quantidade de, pelo menos, vinte marcadores, alegando que 13 loci são eficientes apenas em casos que apresentam material biológico em quantidade suficiente, com bom estado de conservação e provenientes de fonte única, amostras essas raras em análises criminais (KATSANIS; WAGNER, 2013).

Os marcadores STRs localizados nos cromossomos autossômicos, são os mais utilizados na rotina forense, por apresentarem, alto grau de polimorfismo, localização em diferentes cromossomos, reprodutibilidade em reações multiplex e baixa taxa de mutação. Por essas características, os STRs autossômicos, tornaram-se os marcadores mais importantes nos casos de identificação humana, paternidade criminal, ou na ligação entre suspeito e vestígio (GIGONZAC, 2013).

Primeiramente, os exames se baseavam em análise utilizando marcadores do tipo STR localizados nos cromossomos autossômicos, depois iniciaram estudos com marcadores localizados no cromossomo $\mathrm{Y}$, o qual se apresenta apenas em indivíduos do sexo masculino. Esses marcadores são muito utilizados para complementar o resultado do exame, principalmente em casos de violência sexual, onde pode ocorrer amplificação preferencial do material da vítima que, na maioria das vezes, encontra-se em maior quantidade. Porém, algumas limitações são observadas nesses marcadores, como, por exemplo, seu pequeno poder de discriminação, pois os indivíduos do sexo masculino de uma mesma família compartilham a mesma herança haplotípica, ou seja, o mesmo perfil genético, salvo em casos de presença de mutações (SANTOS, 2014; TORRES, 2014).

Em alguns exames houve a necessidade de se ampliar o número de marcadores moleculares com o objetivo de se aumentar a capacidade de distinção das amostras, iniciando-se o estudo de sequências no cromossomo $X$. Este marcador também pode ser utilizado para aumentar o poder de discriminação dos exames moleculares. Seu modo de herança apresenta muitas peculiaridades, pois se processa ora como marcador uni parental ora bi parental, dependendo do gênero sexual estudado (NADEEM et al., 2009). Sabe-se também que em relação aos cromossomos autossômicos, o cromossomo X, apresenta menor taxa de mutação (ZARRABEITIA et al., 2009).

\section{Características do Cromossomo $\mathbf{X}$}

Indivíduos do sexo feminino possuem duas vezes mais o número de cópias de genes do cromossomo $X$ quando comparados com indivíduos do sexo masculino. Para tornar isso proporcional, um dos cromossomos $\mathrm{X}$ da mulher é inativado durante seu desenvolvimento, sendo a inativação transferida a todas as células. Durante a ovogênese ocorre a reativação do segundo cromossomo $X$ feminino que se recombina com o primeiro. No sexo masculino, a recombinação do cromossomo $X$ ocorre nas regiões denominadas pseudoautossômicas, as quais são encontradas nas terminações dos cromossomos sexuais. Estas regiões possuem fundamental importância na segregação normal dos cromossomos $\mathrm{X}$ e $\mathrm{Y}$ durante a meiose (KOBACHUK, 2012).

O cromossomo $X$ representa $5 \%$ do genoma das células femininas e $2,5 \%$ das células masculinas, sendo formado por aproximadamente 155 megapares de bases. Podemos citar, como suas características, sua baixa densidade gênica; presença de 1.098 genes, totalizando $4 \%$ dos genes humanos; altamente rico em regiões repetitivas, representadas por $56 \%$ da molécula de DNA deste cromossomo (MARTINS, 2008b). Em estudos realizados neste cromossomo, têm-se registros de cerca de cento e cinquenta e três mil, cento e quarenta e seis (153.146) polimorfismos de nucleotídeos únicos (SNPS) (ROSS et al., 2005).

Aplicabilidades do uso de marcadores moleculares situados no cromossomo $\mathrm{X}$

A literatura científica apresenta soluções de casos complexos de paternidade utilizando a análise de marcadores moleculares situados no cromossomo $\mathrm{X}$ (KOBACHUK, 2012). O polimorfismo presente nesse cromossomo vem atraindo cada dia mais a atenção de pesquisadores. Inúmeros estudos na população brasileira demonstraram que vários marcadores moleculares situados no cromossomo $X$ já são validados para uso forense, sendo que estes apresentam resposta no que tange sobre a variabilidade desses polimorfismos na população (CAINÉ et al., 2007; CAINÉ et al., 2010; GUSMÃO et al., 2009; LEITE et al., 2009; MARTINS et al., 2008a; MARTINS et al., 2009; MARTINS et al., 2010a; MARTINS et al., 2010b; PENNA et al., 2011; RODRIGUES et al., 2010; RODRIGUES et al., 2011; SILVA et al., 2010; TAVARES et al., 2008).

Na rotina forense, os marcadores do tipo STR mais utilizados são os localizados nos cromossomos autossômicos e no Y (TOMAS et al., 2015). Esses marcadores, na maioria dos casos, são suficientes para obter-se uma conclusão, 
porém casos complexos de identificação humana, principalmente paternidade, podem necessitar de marcadores moleculares situados no cromossomo X (X-STRs). Alguns casos podem ser solucionados utilizando-se somente $X$ -STRs, já em outros casos, esses marcadores servem para complementar a análise dos autossômicos e aumentar a confiabilidade do exame de DNA (AULER-BITTENCOURT et al., 2015; SZIBOR, 2007).

Os X-STRs se caracterizam por apresentarem maiores valores de Mean Exclusion Chance (MEC) em relação aos autossômicos. Isso significa que estes marcadores possuem um poder de discriminação maior que os autossômicos como, por exemplo, em casos em que o suposto pai e criança do gênero sexual feminino não possuem nenhum vínculo genético, proporcionando, assim, a exclusão de paternidade. Em virtude disso, mesmo com a análise de poucos X-STRs, o poder estatístico obtido pode ser suficiente (BINI et al., 2015; SZIBOR et al., 2003).

A maior capacidade de exclusão dos X-STRs, ocorre devido a diferença da quantidade de alelos desses marcadores quando comparado aos autossômicos em indivíduos do sexo masculino. Estes apresentam dois alelos em cada marcador autossômico, mas apenas um alelo em cada marcador sexual do cromossomo X. Portanto, o pai transfere para sua filha $100 \%$ do seu perfil haplotípico do cromossomo $\mathrm{X}$, diferente do que ocorre nos cromossomos autossômicos, onde o pai transfere $50 \%$ da sua informação genética para a filha (MARTINS, 2011). Os marcadores X-STRs empregados na identificação humana, estão situados em regiões não recombinantes entre os cromossomos sexuais, sendo que na mulher a recombinação ocorre entre os cromossomos $X$, permitindo grande variabilidade desses marcadores (KOBACHUK, 2012; MARTINS, 2008b).

Devido às características citadas anteriormente, a maior aplicabilidade do polimorfismo do cromossomo $\mathrm{X}$ se observa nos testes de vínculo genético com exclusão de paternidade, como por exemplo, quando não há material biológico do suposto pai, onde se tem a possibilidade de se reconstruir o perfil genético do investigado a partir da análise de perfis de parentes. Nesses casos quando se utilizam apenas marcadores moleculares autossômicos, frequentemente as análises ficam incompletas, pois para uma boa reconstrução do perfil genético do suposto pai, faz-se necessário a disponibilidade do material biológico de inúmeros parentes. Essas análises ocorrem com frequência em guerras, desastres em massa, dentre outros casos (BECKER et al., 2008; TARIQ et al., 2008).

Quando o teste de paternidade envolve a análise de duo entre pai e filho, os X-STRs, são dispensáveis, já que indivíduos do sexo masculino não herdam o cromossomo $X$ do pai, e sim, da mãe. No entanto, se o duo analisado for pai e filha, esses marcadores são extremamente importantes, principalmente em casos de amostras degradadas, provenientes de casos de exumação. Para duo entre mãe e filha, os X-STRs não apresentam nenhuma vantagem em relação aos marcadores autossômicos. No entanto, em duos onde são analisados mãe e filho, esses marcadores são mais vantajosos quando comparados aos marcadores autossômicos (SZIBOR, 2007).

Estudos realizados no caso de análise de meias-irmãs utilizando marcadores moleculares situados nos cromossomos autossômicos demonstram um pequeno poder de exclusão em face da grande variabilidade alélica. Já em análise entre irmãs ou meias-irmãs utilizando os marcadores moleculares localizados no cromossomo X, é possível observar um maior poder de resolução, isso porque indivíduos do sexo feminino, supostamente filhas do mesmo pai, obrigatoriamente compartilham um mesmo alelo em cada marcador. Assim, estudos demonstram que a presença de quatro diferentes alelos em um único marcador analisado pode concluir pela exclusão de paternidade, mesmo quando os materiais biológicos do pai e parentes não estão disponíveis (KOBACHUK, 2012).

Em outro estudo realizado em um caso de meias-irmãs foi possível a solução do mesmo utilizando apenas quatro marcadores moleculares do tipo STR situados no cromossomo $X$, enquanto que utilizando quinze marcadores moleculares localizados nos cromossomos autossômicos não houve a possibilidade de se solucionar o caso (TURRINA; ATZEI; LEO, 2007).

Silveira et al. (2007) expediram casos com resultados inconclusivos devido à presença de mutações paternas quando analisaram quatro complexos casos de paternidade, envolvendo dois trios (mãe/filha/suposto pai) e duas duplas (filha/suposto pai). A alternativa encontrada para a solução foi analisar oito marcadores X-STRs em todos os casos, sendo que o haplótipo dos supostos pais mostrou-se diferente dos apresentados pelas supostas filhas, concluindo assim, como exclusão de paternidade. Em casos de inconsistência genética comprovada após a análise dos cromossomos autossômicos, a análise do cromossomo $X$ torna-se um importante aliado na conclusão desses casos (SILVEIRA et al., 2007).

Casos de estupro ou incesto, que leve a gravidez da vítima, a gestação pode ser legalmente interrompida. Nessas situações, se o feto for do sexo feminino, os X-STRs também podem ser úteis, pois não é possível obter uma amostra pura quando há interrupção de gravidez com tempo de 6 a 8 semanas. Nestes casos, por se tratar de feto do sexo feminino, apenas marcadores autossômicos e do X podem ajudar, com a prova de paternidade incidindo nos alelos amplificados que não coincidem com os da mãe. Portanto, a probabilidade de exclusão de indivíduos falsamente acusados é maior em relação aos autossômicos nesses casos, uma vez que pessoas do sexo masculino apresentam apenas um alelo para os X-STRs (SZIBOR, 2007).

Schmidtke et al. (2004) demostraram uma das várias aplicações do uso de marcadores no cromossomo $X$ em um suposto caso de incesto, onde tinham como possibilidades de ser o pai, o próprio pai da vítima ou o namorado. O material biológico do pai da vítima não estava disponível, porém foi possível a resolução do caso apenas com 
o material da vítima, da mãe da vítima e do feto, que foi coletado durante um pré-natal na vilosidade coriônica. Por herança, a vítima possuía em seu genótipo $100 \%$ do cromossomo $X$ de seu pai, assim, caso aparecesse algum alelo diferente dos presentes na mãe, a possibilidade de que o pai da vítima fosse também o pai do feto, seria excluída. Neste caso, foram analisados 16 marcadores moleculares localizados no cromossomo $X$, sendo que em 12 marcadores, mãe e feto não compartilhavam alelos. Portanto, a possibilidade de incesto foi excluída (SCHMIDTKE et al., 2004).

\section{CONCLUSÃO}

A análise de DNA iniciou com estudos de marcadores moleculares situados nos cromossomos autossômicos e no Y com aplicação em testes de paternidade e na análise criminal. Esses marcadores possuem alto poder de inclusão em amostras degradadas e ínfimas. Porém, em alguns casos a solução somente pode ser obtida ampliando os tipos de marcadores, sendo em casos forenses a introdução dos marcadores microssatélites (STRs) uma excelente ferramenta de análise.

Vários marcadores moleculares situados no cromossomo $X$ se mostraram indispensáveis em alguns casos forenses, que não poderiam ser solucionados utilizando marcadores nos cromossomos autossômicos e no Y. A principal aplicabilidade do polimorfismo do cromossomo $X$ situa-se nos casos complexos de identificação humana que não poderiam ser solucionados devido à ausência do material biológico de parentes.

\section{REFERÊNCIAS}

ANDERSON, S. et al. Sequence and organization of the human mitochondrial genome. Rev. Nature,[s. I], v. 290, n. 5806, p. 457-465, Apr. 1981.

AULER-BITTENCOURT, E. et al. Exploring the applicability of analysing $X$ chromosome STRs in Brazilian admixed population. Sci. justice, Harrogate, v. 55, n. 5, p. 323-328,Sept.2015.

BECKER, D. et al. Population genetic evaluation of eight X-chromosomal short tandem repeat loci using Mentype Argus X-8 PCR amplification kit. Forensic Sci. Int. Genet., Irlanda, v. 2, n. 1, p. 69-74, Jan. 2008.

BINI, C. et al. Expanding X-chromosomal forensic haplotype frequencies database: Italian population data of four linkage groups. Forensic Sci. Int. Genet., Irlanda , v. 15, p. 127-130, mar. 2015.

BONACCORSO, N. S. Aplicação do exame de DNA na elucidação de crimes. 2005. 193f. Dissertação (Mestrado) - Faculdade de Direito, Universidade de São Paulo, São Paulo, 2005.

BUDOWLE, B.; DAAL, A. V. Forensically relevant SNP classes. Biotechniques, Natick, v. 44, n. 5, p. 603-610, Apr. 2008.

BUTLER, J. M. Forensic DNA Typing: biology, technology, and genetics of STR markers. New York: Elsevier Academic Press, 2005. 688 p.

BUTLER, J. M.; HILL, C. R. Biology and genetics of new autosomal STR loci useful for forensic DNA analysis. Forensic Science Review, [s. I.], v. 24, p. 15-26, 2012.

CAINÉ, L. M. et al. Genetic data of a Brazilian population sample (Santa Catarina) using an X-STR decaplex. J. forensic leg. med., Kidlington, v.
17 , n. 5, p. 272-274, July 2010.

CAINÉ, L. M. et al. Genetic data of four X-chromosomal STRs in a population sample of Santa Catarina, Brazil. J. forensic sci., Philadelphia, v. 52, n. 2, p. 502-503, Mar. 2007.

CHEN, D. et al. Use of X-linked short tandem repeats loci to confirm mutations in parentage caseworks. Clin. chim. acta, Amsterdam, v. 408, p. 29-33, Oct. 2009.

FRUMKIN, D. et al. Authentication of forensic DNA samples. Forensic Sci. Int. Genet., Irlanda, v. 4, n. 2, p. 95-103, Feb. 2010.

GIGONZAC, T. C. V. Caracterização genética da população do estado de Goiás baseada em marcadores STRs autossômicos e do Cromossomo X. 2013. 83f. Tese (Doutorado) - Instituto de Ciências Biológicas, Universidade Federal de Goiás, Goiás, 2013.

GODINHO, N. M. de O. Banco de dados de DNA: uma ferramenta a serviço da justiça. REBESP., Goiânia, v. 7, n. 2, p. 20-30, 2014.

GOÉS, A. C. de S. Análise de regiões polimórficas do DNA com o objetivo de estabelecer vínculos genéticos, identificar restos mortais ou realizar perícias criminais. 2010. Disponível em: <http://www.crbm1.gov.br/ bio65/artigocien_65.asp>._Acesso em: 25 out. 2015.

GRIFFITHS, A. J. F. et al. Introdução à Genética. 9. ed. Rio de Janeiro: Guanabara Koogan, 2009. 710 p.

GUSMÃO, L. et al. A GEP-ISFG collaborative study on the optimization fan $X-S T R$ decaplex: data on 15 Iberian and Latin American populations. Int. j. legal med., Heildeberg, v. 123, n. 3, p. 227-234, Maio 2009.

HOU, Y. P. Forensic DNA typing in China. Leg. med., Tokyo, v. 11, p. 103-105, Apr. 2009.

JEFFREYS, A. The man behind the DNA fingerprints: an interview with Professor Sir Alec Jeffreys. Investig. Genet., Londres, v. 4, p. 4-21, Nov. 2013.

JEFFREYS, A. J.; BROOKFIELD, J. F. Y.; SEMEONOFF, R. Positive identification of an immigration test-case using human DNA fingerprints. Nature, London, v. 317, n. 6040, p. 818-819, Oct. 1985.

JOBIM, L. F.; COSTA, L. R. da S.; SILVA, M. da. Identificação Humana 2. ed. Campinas-SP: Milennium, 2005. 302 p.

JOBLING, M. A. Curiosity in the genes: the DNA fingerprinting story. Investig. Genet., Londres, v. 4, p. 20, Nov. 2013.

KATSANIS, S. H.; WAGNER, J. K. Characterization of the standard and recommended CODIS markers. J. forensic sci., Philadelphia, v. 58, p. 169-172, Jan. 2013.

KOBACHUK, L. D. G. Estudo de frequências alélicas de dez locos STR's do cromossomo $X$ na população do Estado do Paraná e sua contribuição na identificação humana. 2012. 88 f. Dissertação (Mestrado) - Departamento de Genética, Universidade Federal do Paraná, 2012.

LEITE, F. P. N. et al. Linkage disequilibrium patterns and genetic structure of Amerindian and Non-Amerindian Brazilian populations revealed by long-range $X$ - STR markers. Am. j. phys anthropol., Philadelphia , v. 139 , n. 3, p. 404-412, July 2009.

LI, H. et al. A multiplex PCR for $4 \mathrm{X}$ chromosome STR markers and population data from Beijing Han ethnic group. Leg. med., Tokyo, v. 11, n. 5, p. 248-250, Sept. 2009.

LI, S. et al. SOAPindel: Efficient identification of indels from short paired reads. Genome res., New York, v. 23, n. 1, p. 195-200, Jan. 2013.

MARTINS, J. A. Estudo de polimorfismos do cromossomo $X$ na população da região Sudeste do Brasil. 2011. 117f. Tese (Doutorado) - Fa- 
culdade de Ciências Farmacêuticas, Universidade Estadual Paulista Júlio de Mesquita Filho, Araraquara, 2011.

MARTINS, J. A. et al. X-chromosome genetic variation in São Paulo State (Brazil) population. Ann. hum. biol., London, v. 37, n. 4, p. 598603, 2010a.

MARTINS, J. A. et al. Genetic profile characterization of $10 \mathrm{X}$-STRs in four populations of the southeastern region of Brazil. Int. j. legal med., Heidelberg, v. 124, n. 5, p. 427-432, 2010 b.

MARTINS, J. A. et al. Genetic data of $10 \mathrm{X}$-chromosomal loci in Vitoria population (Espírito Santo State; Brazil). Forensic Sci. Int. Genet, Irlanda, v. 2, n.1, p. 394-395, Dec. 2009.

MARTINS, J. A. et al. Population genetic data of Five X-chromosomal loci in Bauru (São Paulo, Brazil). Forensic Sci. Int., [s. I] v. 1, n. 1, p. 155-156, 2008a.

MARTINS, J. A. et al. Estudo de frequências alélicas de STRs do cromossomo X na população brasileira de Araraquara-SP. 2008. 122 f. Dissertação (Mestrado) - Faculdade de Ciências Farmacêuticas, Universidade Estadual Paulista, 2008b.

MATTE, C. H. F. Indels autossômicos e do cromossomo X em uma amostra da população do Rio Grande do Sul para possíveis aplicações forenses. 2011. 26 f. Dissertação (Mestrado) - Faculdade de Biociências, Pontifícia Universidade Católica do Rio Grande do Sul, Porto Alegre, 2011.

NADEEM, A. et al. Development of pentaplex PCR and genetic analysis of $X$ chromosomal STRs in Punjabi population of Pakistan. Mol. Biol. reports, Basel, v. 36, n. 7, p. 1671-1675, Sept. 2009.

OLIVEIRA, T. Análise da frequência alélica de 15 loci STR na população do Rio Grande do Norte. 2012. 77 f. Dissertação (Mestrado) - Faculdade de Ciências Farmacêuticas, Universidade do Rio Grande do Norte, Natal, 2012.

PENNA, L. S. et al. Development of two multiplex PCR systems for the analysis of $14 \mathrm{X}$-chromosomal STR loci in a southern Brazilian population sample. Int. j. legal med., Heidelberg, v.126, n. 2, p. 327-330, Mar. 2011.

RODRIGUES, E. M. R. et al. Extensive survey of $12 \mathrm{X}$-STRs reveals genetic heterogeneity among Brazilian populations. Int. j. legal med., Heidelberg, v. 125, n. 3, p. 445-452, Maio 2011.

RODRIGUES, E. M. R. et al. Genetic data of twelve X-STRs in Japanese immigrant population resident in Brazil. Forensic Sci. Int. Genet., [s.I.], v. 4, n. 2, p. e57-e58, Feb. 2010.

ROSS, M. T. et al. The DNA sequence of the human $X$ chromosome. Nature, London, v. 434, n. 7031, p. 325-337, Mar. 2005

SANCHES, N. Análise de polimorfismos da região controle do DNA mitocondrial em indivíduos nascidos e resisdentes no estado do Espírito Santo para utilização na identificação humana. 2013. 83 f. Dissertação (Mestrado) - Faculdade de Ciências Farmacéuticas, Universidade Estadual Paulista Júlio de Mesquita Filho, Araraquara, 2013.

SANTOS, S. Identificação humana como ferramenta de investigações criminais: estudo de frequências alélicas de marcadores de interesse forense no Estado de Pernambuco. 2014. 168 f. Tese (Doutorado) Centro de Ciências Biológicas, Universidade Federal do Pernambuco,
Recife, 2014.

SCHMIDTKE, J. et al. Prenatal exclusion without involving the putative fathers of an incestuous father-daughter parenthood. Prenat. Diagn., Chichester, v. 24, n. 8, p. 662-664, Ago. 2004.

SILVA, E. C. da et al. Estratégias para identificação humana: do geral ao genoma. REBES, Pombal, v. 3, n. 3, p. 46-52, 2013.

SILVA, I. H. F. da et al. An X-chromosome pentaplex in two linkage group: Haplotype data in Alagoas and Rio de Janeiro populations from Brazil. Forensic Sci. Int. Genet., [s. I.], v. 4, n. 4, p. 95-100, 2010.

SILVEIRA, D. et al. Use of X-linked short tandem repeat loci in routine parentage casework. Transfusion, Philadelphia, v. 47, n. 6, p. 10501053, June 2007.

SZIBOR, R. X-chromosomal markers: past, present and future. Forensic Sci. Int. Genet., [s. I.], v. 1, n. 2, p. 93-99, June 2007.

SZIBOR, R. et al. Use of X-linked markers for forensic purposes. Int. j. legal med., Heidelberg, v. 117, n. 2, p. 67-74, Feb. 2003.

TAN, E. et al. Fully integrated, fully automated generation of short tandem repeat profiles. Investig. Genet., Finlândia, v. 4, n. 1, p. 1-16, Ago. 2013.

TARIQ, M. A. et al. Allele frequency distribution of $13 \mathrm{X}$-chromosomal STR loci in Pakistani population. Int. j. legal med., Heidelberg, v. 122, n. 6, p. 525-528, Nov. 2008.

TAVARES, C. C. et al. Population data for six $X$ chromosome STR loci in a Rio de Janeiro (Brazil) sample: Usefulness in forensic casework. FSI genetics supplement series, v. 1, n. 1, p. 164-166, Ago. 2008.

TOMAS, C. et al. Results for five sets of forensic genetic markers studied in a Greek population sample. Forensic Sci. Int. Genet., [s.I.], v. 16, p. 132-137, Jan. 2015.

TORRES, S. R. R. Avaliação da estrutura genética da população atual de Santa Catarina com diferentes marcadores moleculares para aplicação na Genética Forense. 2014. 221 f. Tese (Doutorado) - Centro de Ciências Biológicas, Universidade Federal de Santa Catarina, Florianópolis, 2014.

TURRINA, S.; ATZEI, R.; LEO, D. Polymorphism of four X-chromosomal STRs: DXS7423, DXS7424, DXS8378 and DXS6809 in a North Italian population sample and their use in kinship testing. Forensic sci. int., Lausanne, v. 168, p. 241-243, Maio 2007.

VELHO, J. A.; GEISER, G. C.; ESPINDULA, A. Ciências Forenses: uma introdução às principais áreas da Criminalística Moderna. 2. ed. São Paulo: Millenium, 2013. $496 \mathrm{p}$.

WATSON, J. D.; CRICK F. H. Molecular structure of nucleic acids; a structure for deoxyribose nucleic acid. Nature, London, v. 171, n. 4356, p. 737-738, Apr. 1953.

ZARRABEITIA, M. T. et al. Analysis of $10 \mathrm{X}$-linked tetranucleotide markers in mixed and isolated populations. Forensic Sci. Int. Genet., [s.I.], v. 3, p. 63-66, Mar. 2009.

ZIETKIEWICZ, E. et al. Current genetic methodologies in the identification of disaster victims and in forensic analysis. J. appl. genet., Pozna, v. 53, n.1, p. 41-60, Feb. 2012.

Submetido em: 02/12/2015

Aceito em: 07/06/2016 